\title{
Low frequency jet ventilation for stent insertion in a patient with tracheal stenosis
}

\author{
[La ventilation en jet de basse fréquence pendant l'insertion d'un tuteur chez un \\ patient victime de sténose trachéale]
}

Anis S. Baraka MD FRCA, Sahar S. Siddik MD FRCA, Samar K. Taha MD, Maya I. Jalbout MD, Faraj M. Massouh MD

Purpose: Evaluate oxygen jet ventilation in a patient with tracheal stenosis undergoing stent insertion.

Clinical features: Manual intermittent low frequency oxygen jet ventilation was used during general anesthesia for fibreoptic bronchoscopy and stent insertion in a patient with tracheal stenosis. Oxygen jets were delivered via a Sander's injector adapted to the proximal end of the endotracheal tube on one side, and open to room air on the other side. Adequate oxygenation and carbon dioxide removal were ensured throughout the procedure.

Conclusion: Low frequency jet ventilation in a patient with tracheal stenosis provided adequate ventilation as well as a nonobstructed field during fibreoptic bronchoscopy and stent insertion.

Objectif : Évaluer la ventilation en jet avec de l'oxygène chez un patient qui présente une sténose trachéale et qui doit subir la mise en place d'un tuteur.

Éléments cliniques : La ventilation en jet, manuelle et intermittente, avec de l'oxygène, a été utilisée pendant l'anesthésie générale pour la fibroscopie et l'insertion d'un tuteur chez un sujet souffrant de sténose trachéale. L'oxygène a été administré par un injecteur de Sander fixé à la partie proximale de la sonde endotrachéale, d'un côté, et ouvert à l'air ambiant, de l'autre côté. L'oxygénation et l'élimination du gaz carbonique ont été adéquates pendant toute l'intervention.

Conclusion : La ventilation en jet à basse fréquence, utilisée dans un cas de sténose trachéale, a fourni une ventilation suffisante et un champ libre pour la fibroscopie et l'insertion d'un tuteur.
$\mathrm{T}$

RACHEAL stenosis is a feared although increasingly rare complication of prolonged endotracheal intubation or tracheostomy. Various treatment modalities are currently available for the management of tracheal stenosis. These include balloon dilatation, stenting, Nd:YAG laser ablation and surgical resection. ${ }^{1}$ In patients with benign tracheal stenosis, stents provide structural support to alleviate the narrowed segment. Expandable stents have several advantages; they are easily inserted, they preserve ciliary function and they do not interfere with ventilation. In addition, they are dynamic and continue to expand over time. ${ }^{2}$

Airway management in a patient with tracheal stenosis undergoing stent insertion poses a challenge to the anesthesiologist who has to ensure adequate ventilation in the presence of a stenotic segment, and to provide the radiologist with a still and nonobstructed field during stent insertion.

In previous reports, Baraka et al. utilized low frequency jet ventilation in patients undergoing tracheal reconstruction for the management of tracheal stenosis $^{3}$ or excision of tracheal or bronchial tumours. ${ }^{4}$ In the present report, we utilized a Sander's Venturi injector, ${ }^{5}$ attached to the proximal end of the tracheal tube, to deliver manual low frequency intermittent oxygen jet ventilation during stent insertion under general anesthesia in a patient having tracheal stenosis.

Case report

A 17-yr-old man, previously healthy, sustained a blast injury in March 2000 and required tracheal intubation and ventilatory assistance for 15 days. Two weeks following extubation, the patient started complaining of

From the Department of Anesthesiology, American University of Beirut, Beirut, Lebanon.

Address correspondence to: Dr. Anis S. Baraka, Professor and Chairman, Department of Anesthesiology, American University of Beirut,

P.O. Box 113-6044, Beirut, Lebanon. Phone: 961-1-350000, ext. 6380; Fax: 961-1-744464; E-mail: abaraka@aub.edu.lb

Accepted for publication March 27, 2001.

Revision accepted May 2, 2001. 


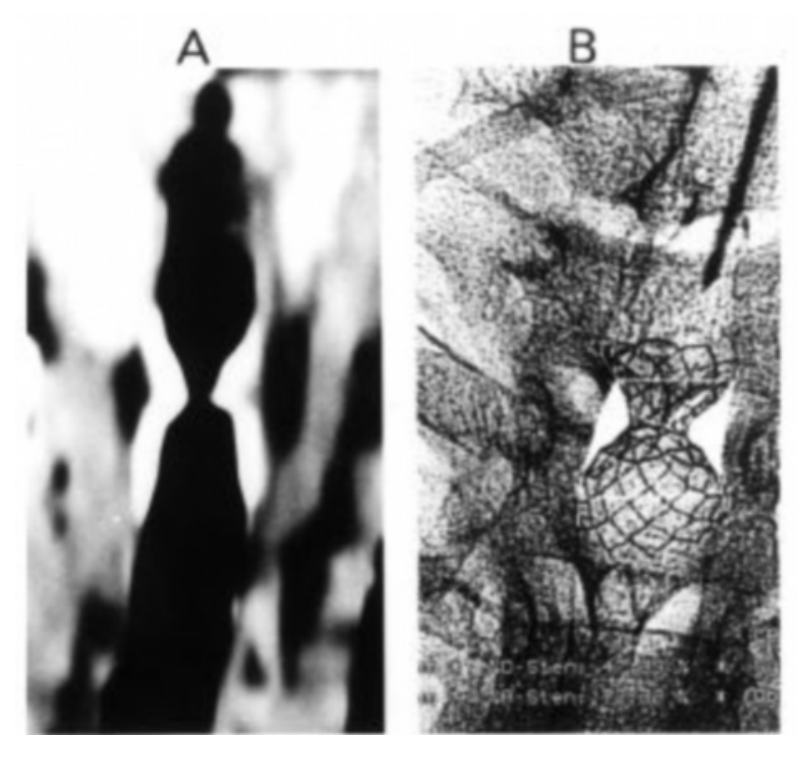

FIGURE 1 A, Coronal section of a computed tomography at the level of tracheal stenosis. B, Fluoroscopic radiograph of the trachea after stent insertion

progressively worsening dyspnea and cough. Lung examination revealed inspiratory stridor with mild chest wall retraction. Arterial blood gases on room air showed mild hypoxemia and $\mathrm{CO}_{2}$ retention, with $\mathrm{PaO}_{2}=75 \mathrm{mmHg}, \mathrm{PaCO}_{2}=46 \mathrm{mmHg}$ and oxygen saturation of $96 \%$. A flow-volume loop monitoring during spontaneous breathing showed a plateau in both inspiratory and expiratory phases. A computed tomography of the neck revealed a $7 \mathrm{~cm}$ long tracheal stenosis (Figure 1A).

The patient was scheduled for stenting of the stenotic trachea. He was premedicated with glycopyrrolate $0.2 \mathrm{mg} \mathrm{im}$. Monitoring included continuous three lead electrocardiography, pulse oximetry and non-invasive blood pressure measurement. Preoxygenation of the patient was achieved by breathing $100 \% \mathrm{O}_{2}$ at $8 \mathrm{~L} \cdot \mathrm{min}^{-1}$ via a tight- fitting face mask for three minutes. Anesthesia was then induced with the single vital capacity breath technique, ${ }^{6}$ using sevoflurane $8 \%$ in oxygen. Manual ventilation was found to be easy; succinylcholine $1.5 \mathrm{mg} \cdot \mathrm{kg}^{-1}$ was administered and a 9F endotracheal tube was inserted under direct laryngoscopy through the vocal cords and was advanced in the trachea until resistance at the site of the stenosis was encountered. Anesthesia was maintained by total iv anesthesia using propofol $0.1 \mathrm{mg} \cdot \mathrm{kg}^{-1} \cdot \mathrm{min}^{-1}$ and succinylcholine drip.

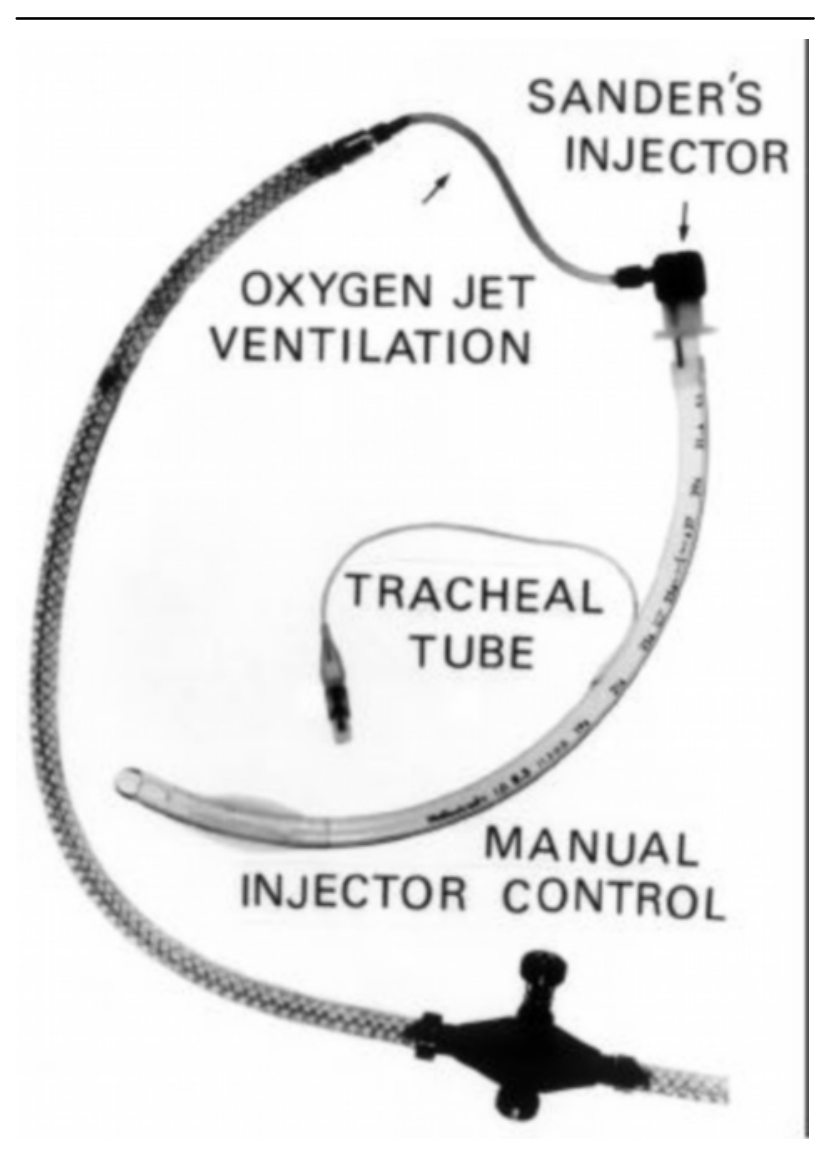

FIGURE 2 A photograph showing the Sander's injector attached on one side to the tracheal tube while its proximal side is kept open to room air. Manual control is used for delivery of intermittent oxygen jets via the injector.

A Sander's injector device open to room air was adapted to the proximal end of the endotracheal tube (Figure 2), and intermittent oxygen jets at a pressure of $50 \mathrm{psi}$ and at a rate of $10 \cdot \mathrm{min}^{-1}$ with an inspiratory: expiratory time (I:E) ratio of $1: 4$ were used to ventilate the patient. A flexible fibreoptic bronchoscope, inserted via the Sander's device and into the endotracheal tube, revealed a circumferential tracheal stenosis $5.5 \mathrm{~cm}$ away from the vocal cords, causing a $75 \%$ luminal obstruction. The distal end of the endotracheal tube was confirmed to be just above the stenotic segment. The fibreoptic bronchoscope was then removed and, under fluoroscopy guidance, a $30 \mathrm{~mm}$ Palmaz stent was deployed across the tracheal stricture using an $18 \times 4 \mathrm{~mm}$ balloon. At the end of the procedure, the diameter of the tracheal lumen at the site of stenosis was $9 \mathrm{~mm}$ (Figure 1B). 
Oxygen jet ventilation was continued throughout the procedure. During stent placement, ventilation was temporarily interrupted for two to three minutes as the trachea was obstructed by the inflated balloon, which may have resulted in the increase of $\mathrm{PaCO}_{2}$ and the decrease of $\mathrm{PaO}_{2}$; prior to stent insertion, $\mathrm{PaCO}_{2}$ was $29 \mathrm{mmHg}$ and $\mathrm{PaO}_{2}$ was $545 \mathrm{mmHg}$, as compared to the corresponding values after stent placement when $\mathrm{PaCO}_{2}$ was $47 \mathrm{mmHg}$ and $\mathrm{PaO}_{2}$ was 182 $\mathrm{mmHg}$. However, no significant alterations in the oxygen saturation, as monitored by pulse oximetry were noted; saturation was maintained above 95\% before, during and after the stent insertion.

After stent insertion, iv anesthesia was discontinued. Following recovery of consciousness and resumption of adequate spontaneous breathing, the trachea was extubated. Arterial blood gases following tracheal extubation and while on face mask $\mathrm{O}_{2}$ of $5 \mathrm{~L} \cdot \mathrm{min}^{-1}$ showed a $\mathrm{PaO}_{2}=107 \mathrm{mmHg}, \mathrm{PaCO}_{2}=37 \mathrm{mmHg}, \mathrm{pH}=7.43$ and oxygen saturation of $98 \%$.

\section{Discussion}

Tracheal stenosis can be secondary to prolonged intubation, tumours or congenital malformations. Resistance to airflow in a conduit is inversely proportional to the fourth power of the diameter, ${ }^{7}$ signs and symptoms become clinically evident as resistance to airflow increases when the airway is narrowed to 5 or $6 \mathrm{~mm}^{8}$

Lesions causing tracheal narrowing can be fixed or dynamic obstructions. Dynamic obstruction can be the result of tumours arising from the neck or the mediastinal structures and can be intrathoracic or extrathoracic. Dynamic obstruction varies with the respiratory cycle. In patients with dynamic extrathoracic obstruction, forced expiration results in a tracheal pressure higher than the pressure around the airway; this leads to a decrease in the obstruction and a normal expiratory flow. During inspiration, a negative intratracheal pressure is developed; the surrounding tissue has a higher pressure that leads to more obstruction of the trachea and a resultant decrease in inspiratory flow. In patients with variable intrathoracic obstruction, forced expiration is associated with a relatively greater increase in pleural pressure leading to compression of the trachea. In inspiration, the tracheal pressure is higher than the pleural pressure with consequent relief of the obstruction. ${ }^{8}$

In contrast with dynamic tracheal narrowing, the airway diameter in patients with fixed airway obstruction does not change with either inspiration or expiration, and air flow is equally hindered with resulting decrease in expiratory and inspiratory flow. ${ }^{8}$ In our patient, the tracheal stenosis constituted a fixed obstruction as shown by a plateau in both expiratory and inspiratory limbs of the flow-volume loop during spontaneous breathing.

Current management of tracheal stenosis includes balloon dilatation, laser ablation, stent placement or surgical resection. Stents can be a definitive treatment for patients with tracheal stenosis who are not candidate for surgery either because of the extent of the tracheal stricture or because of unfavourable medical conditions. ${ }^{1}$ In our patient, stent placement was used as a temporary measure to relieve his worsening dyspnea and stridor until future tracheal reconstructive surgery is performed.

Airway management in a patient with tracheal stenosis undergoing stent insertion poses a challenge to the anesthesiologist who has to ensure adequate ventilation in the presence of a stenotic segment, and to provide the radiologist with a still and nonobstructed field during stent insertion. Stent insertion in a patient with tracheal stenosis can be done through a rigid bronchoscope, ${ }^{9}$ laryngeal mask airway ${ }^{10}$ or endotracheal tube, with the latter allowing more flexibility and greater ease of manipulation of the airway. ${ }^{11}$ In addition, stenting through an endotracheal tube can provide better airway protection.

Stent placement may be performed under topical anesthesia in the awake patient. ${ }^{12,13}$ However, this may be complicated by initial misplacement of the stent ${ }^{2}$ and removal or repositioning of some stents is very difficult. Thus, general anesthesia is preferred for stent placement, with the patient breathing spontaneously. ${ }^{14,15}$ However, during stent insertion, the airway is obstructed and spontaneous breathing will be hindered. Also, tracheal stenosis constitutes a fixed airway obstruction with decreased flow rate across the stenosis during both expiration and inspiration, whether ventilation is spontaneous or controlled. In addition, the supine position and general anesthetics cause a cephalad movement of the dome of the diaphragm with a resultant decrease in lung volume. This will lead to a further increase in dynamic resistance to airflow. ${ }^{8}$

Intermittent oxygen jets have been utilized previously for ventilation of patients with tracheal stenosis undergoing tracheal reconstruction, ${ }^{3}$ as well as in patients having tracheal or bronchial tumours. ${ }^{4}$ In our previous report, the Venturi injector was used as an interface between the tracheal tube on one side and the anesthesia circuit on the other side, and hence inhalation anesthetic-oxygen mixture could be entrained by the intermittent oxygen jets. ${ }^{4}$

In the present report, we used the technique of manual low frequency intermittent oxygen jet ventilation in a patient with tracheal stenosis undergoing 
fibreoptic bronchoscopy and stent insertion under general anesthesia. The proximal end of the Sander's injector is kept continuously open to room air instead of being connected to the anesthesia circuit, in order to provide a still and non-obstructed field during fibreoptic bronchoscopy and stent insertion. In addition, it provides adequate ventilation, since the delivered oxygen jets will create a Venturi effect that results in air entrainment and a marked increase in the total flow across the stenosis. ${ }^{3,5}$ Also, it is postulated that intermittent oxygen jets delivered proximal to the stenotic segment itself may create a Venturi effect which augments rather that hinders ventilation. In our patient, ventilation and oxygenation were adequate throughout the procedure as evidenced by pulse oximetry and by arterial blood gas analysis.

The use of intermittent oxygen jet ventilation can be complicated by the occurrence of barotrauma secondary to the high pressure. ${ }^{16,17}$ Also, the presence of tracheal stenosis can decrease significantly the cross-sectional area that impairs passive exhalation, leading to air trapping with consequent barotrauma. The smaller the cross-sectional area of the tracheal stenosis, the higher the resistance to exhalation will be. ${ }^{16,18}$ In our patient, use of a Sander's injector which is kept open to the atmosphere may have attenuated the jet and minimized the occurrence of barotrauma. ${ }^{19}$ Also, the I:E ratio was $1: 4$ in order to allow enough time for passive exhalation through the stenotic segment, which can prevent gas trapping and dynamic lung hyperinflation. ${ }^{20}$

In summary, the present report shows that, in a patient with tracheal stenosis, intermittent oxygen jet ventilation at 50 psi via a Sander's injector adapted to the proximal end of the tracheal tube can provide adequate ventilation during general anesthesia, as well as a non-obstructed field during fibreoptic bronchoscopy and tracheal stenting.

\section{References}

1 Pinsonneault C, Fortier J, Donati F. Tracheal resection and reconstruction. Can J Anesth 1999; 46: 439-55.

2 Nesbitt JC, Carrasco H. Expandable stents. Chest Surg Clin N Am 1996; 6: 305-28.

3 Baraka $A$. Oxygen-jet ventilation during tracheal reconstruction in patients with tracheal stenosis. Anesth Analg 1977; 56: 429-32.

4 Baraka A, Mansour R, Abu Jaoude C, Muallem M, Hatem J, Jaraki $K$. Entrainment of oxygen and halothane during jet ventilation in patients undergoing excision of tracheal and bronchial tumors. Anesth Analg 1986; 65: 191-4.

5 Sander RD. Two ventilating attachment for bronchoscopes. Del Med J 1967; 39: 170-5.
6 Yurino M, Kimura H A comparison of vital capacity breath and tidal breathings techniques for induction of anaesthesia with high sevoflurane concentrations in nitrous oxide and oxygen. Anaesthesia 1995; 50: 308-11.

7 MacIntosh R, Mushin W, Epstein HG Physics for the Anaesthetist, 3rd ed. Oxford: Blackwell Scientific publication, 1963.

8 Benumof JL. Anesthesia for Thoracic Surgery, $1^{\text {st }}$ ed. Philadelphia: W.B. Saunders company, 1987.

9 Kim H. Stenting therapy for stenosing airway disease. Respirology 1998; 3: 221-8.

10 ramamoto S, Yamada T, Kajikawa S, Arisaka $H$, Nishibe S, Takeda J. Anesthetic management of patients with tracheal stenosis for endoscopic treatment: usefulness of laryngeal mask airway. Masui 2000; 49: 184-6.

11 Nomori H, Horio H, Suemasu K Dumon stent placement via endotracheal tube. Chest 1999; 115: 582-3.

12 Coolen D, Slabbynck H, Galdermans D, Van Schaardenburg C, Mortelmans LL. Insertion of a selfexpandable endotracheal metal stent using topical anaesthesia and a fiberoptic bronchoscopy: a comfortable way to offer palliation. Thorax 1994; 49: 87-8.

13 Spinelli P, Meroni E, Cerrai FG Self-expanding tracheobronchial stents using flexible bronchoscopy: preliminary clinical experience. Surg Endosc 1994; 8: 411-3.

14 Inada S, Takasu A, Shindo J, Koyama T, Minakuchi K, Nakamura T. Anesthesia for tracheobronchial stent insertion. Masui 1998; 47: 856-60.

15 Fujii K, Okida M, Fujioka $\Upsilon$, Kobayashi M, Fujimoto $M$. General anesthesia for expandable endotracheobronchial metal stent insertion. Masui 1996; 45: 464-70.

16 Baraka AS. Tension pneumothorax complicating jet ventilation via a cook airway exchange catheter. Anesthesiology 1999; 91: 557-8.

17 Chang J-L, Bleyaert A, Bedger $R$ Unilateral pneumothorax following jet ventilation during general anesthesia. Anesthesiology 1980; 53: 244-6.

18 Dworkin R, Benumof JL, Benumof R, Karagianes TG The effective tracheal diameter that causes air trapping during jet ventilation. J Cardiothorac Anesth 1990; 4: 731-6.

19 Baraka AS. Tension pneumothorax complicating jet ventilation via a cook airway exchange catheter (Letter). Anesthesiology 1999; 91: 297-8.

20 Benumof JL. Airway exchange catheters. Simple concept, potentially great danger (Editorial). Anesthesiology 1999; 91: 342-4. 